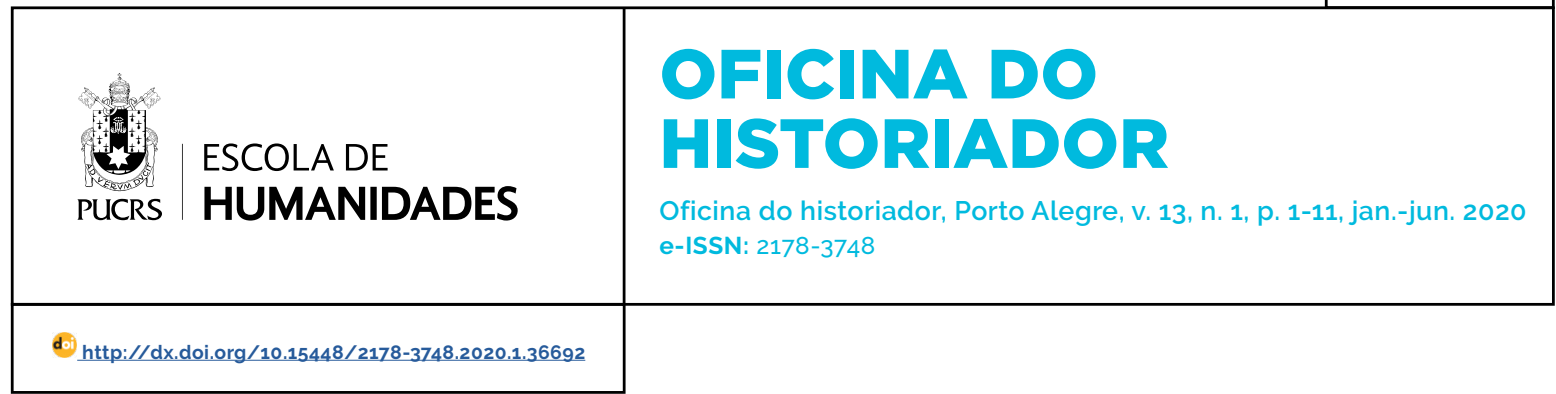

\title{
Materiais contra a mutabilidade: o caso da oleira surda-muda nos registros de Freire Alemão no Ceará (1859-1861)
}

\author{
Materials against mutability: the case of deaf-mute pottery in the records of Freire \\ Alemão in Ceará (1859-1861)
}

\section{Ana Paula Gomes \\ Bezerra $^{1}$ \\ orcid.org/0000-0003-0441-892 \\ ana.bezerra.001@acad.pucrs.br}

\section{Filipi Pompeu ${ }^{1}$}

orcid.org/0000-0002-5929-3237

filipi.pompeu@gmail.com

Recebido em: 22 dez. 2019 Aprovado em: $18 \mathrm{fev} .2020$ Publicado em: 14 jun. 2020.

\section{(c) (1)}

Artigo está licenciado sob forma de uma licença Creative Commons Atribuição 4.0 Internacional.
Resumo: A Arqueologia vem atravessando um período onde as suas relações com seu objeto de pesquisa, os materiais, estão sendo atualizadas. Na situação em questão pretendemos analisar, a partir do viés sensorial-fenomenológico, a interação específica entre uma espécie de louça utilitária única, os materiais que nela resultam, e a sua fabricante, uma oleira muda. Argumenta-se, com base em estudos da cultura Surda/Muda, que a condição da oleira na verdade contribui para um desenvolvimento aprimorado de outros sentidos que ajudam a explicar a peculiaridade de sua produção - fato este que passa despercebido por seu relator, Freire Alemão. Reforçando esta proposição, alia-se uma análise a partir da narrativa do autor sobre; o processo de produção de louças populares; o sistema de práticas de boas maneiras que exigia a renovação de conjuntos de louças; e o contexto do comércio, importação e produção cearense de cerâmica europeia e local. Pretende-se desta forma destacar a produção desta louça "Surda/Muda" como uma forma de comunicação e expressão em um mundo onde o conceito de cultura Surda/Muda ainda não existia.

Palavras-chave: Arqueologia sensorial. Fenomenologia. Viajante. Surda-muda. Cerâmica

Abstract: Archeology has been going through a period where its relationships with its research object, materials, are being updated. In the situation in question, we intend to analyze, from the sensorial-phenomenological bias, the specific interaction between a single utilitarian crockery, the materials that result from it, and its maker, a silent pottery. It is argued, based on studies of the Deaf / Muda culture, that the condition of the potter actually contributes to an improved development of other senses that help to explain the peculiarity of its production - a fact that goes unnoticed by its Freire Alemão. Reinforcing this proposition, an analysis is based on the narrative of the author on; the process of producing popular crockery; the system of good manners that required the renovation of sets of dishes; and the context of European and local ceramic trade, import and production in Ceará. The intention is to highlight the production of this dish" Deaf-mute" as a form of communication and expression in a world where the concept of Deaf / Muda culture did not yet exist.

Keywords: Sensory archeology. Phenomenology. Traveler. Deaf-mute. Ceramics.

\section{Introdução}

O presente artigo tem como objetivo analisar, a partir dos relatos de um viajante na segunda metade do século XIX, a inserção de uma oleira surda-muda, na região de Forquilha ${ }^{2}$, no Ceará, através de sua cerâmica em dois mundos distintos, o industrializado e o artesanal. Pode-se observar a 
relação entre a História e a Arqueologia por meio da materialidade presente e descrita nos relatos supracitados, permitindo analisar alguns aspectos que tangem a especificidade deste caso, uma oleira surda-muda inserida em um contexto peculiar.

Uma das características que constituem a Arqueologia parece ser definida como um negativo dos materiais, substâncias e formas que esses assumem. O termo negativo, de preferência, deveria estar entre aspas para indicar que na verdade seu sentido não é tão literal ou tão rigoroso; mas aqui o adotamos não como uma proibição, e sim como uma distinção frente a algo que não está lá. É claro que isso é uma tautologia falsa: a presença positiva de testemunhos e observações diretas dos materiais em utilização fornece subsidios para a exploração das relações sociais travadas através das coisas materializadas (ainda mais se essas relações nos são elaboradas especificamente com linguagem fonética articulada). Na verdade, a Arqueologia parece possuir essa pecha de incompletude, dependência e subordinação a contextos etnográficos, que, diante da baixa autoestima da disciplina material, ganham proporção e um valor informativo que nem sempre correspondem a uma equivalência qualitativa real - ou seja, nutrem certa tautologia falsa ao mesmo tempo que fundamentam outra (HOLBRAAD, 2009)

A perspectiva de que a voz e o falar são por vezes tidos como partições fundamentais da comunicação, que, na verdade, depende de articulação de elementos diversos que não se restringem a vocalização. A compreensão material dos Surdos (LAAD, 2012)33 contém importantes reflexões sobre como a Arqueologia pode se relacionar com a alteridade dos materiais, pois as pessoas Surdas, tão imediatamente colocadas na posição de Outro por Ouvintes, possuem uma relação diferencial com materiais. Não nos estenderemos em uma Sociologia da Surdez, pois essa não é a nossa área; inclusive pretendemos nos ater a um modelo arqueológico criticável em alguns aspectos por sua - quiçá excessiva - aproximação ao materialismo histórico. Mas, ao nos aproximamos do universo da Surdez, podemos obter diferentes perspectivas sobre como articular a presença dos materiais e seus processos de materialização como a construção de um mundo-outro e de uma outra alteridade.

A análise de um curioso relato do século XIX foi o impulso dessas ideias. Se trata do registro de uma olaria caseira operada por uma moça surda-muda e a sua familia. Sua louça, "mui preta e lustrosa", diferente de tudo o que o cronista havia visto, tinha o mais excêntrico dos corantes: excrementos de cavalo. Além da referida "moça muda"4 essa inserida em dois mundos, o industrializado, a partir de modelos que se assemelhavam ao gosto europeu e o artesanal, onde sua produção era feita por famílias de oleiras para uso cotidiano.

Tais registros só foram possiveis através do Diário de Viagem de Francisco Freire Alemão, pois através de suas descrições permite ao leitor perceber o papel da moça-muda. De acordo com os historiadores Minuzzi e Tomazzi

Os relatos de viagem são muito diversos, pois possuem uma grande liberdade de estilo de escrita, onde a vontade do viajante predomina e não existe formalidade para serem seguidas. Devido a esta questão, cada relato se mostra único e, por vezes, difícil de agrupá-lo com outros relatos que podem abranger diários pessoais ou relatórios de viagem, dependendo do ponto de vista do estudioso que os define (MINUZZI; TOMAZZI, 2016, p. 242).

Tais relatos representam descrições do cotidiano e fornecem elementos necessários para compreendermos o contexto de tal relato e sua relevância. De acordo com Núncia S. Constantino (2012, p. 8) "a literatura de viagem sempre serviu como fonte de conhecimento histórico", podemos ainda afirmar que a mesma pode ser usada por arqueólogos também, e fornecem elementos que possibilitam analisar alguns contextos arqueológicos, onde a cultura material pode estar inserida.

\footnotetext{
3 Onde a maiúscula (Surdez) corresponde a uma identificação com o caractere cultural da surdez e a comunidade Surda. A minúscula (surdez) com a condição audiológica (LADD, 2013, glossário conceitual)

4 Termo usado pelo botânico Francisco Freire Alemão, em seu Diário, escrito em 1859
} 
Para a Constantino (2012, p. 10) "é preciso considerar que tais relatos são sempre representações, ou 'reinvenções de realidades'". Destacamos que os relatos de viagem analisados destacam a perspectiva do viajante ao descrever o caso estudado, e como esse discorre ao longo das páginas de seu diário e das suas impressões acerca do trabalho realizado pela referida oleira.

A fala de Freire Alemão insere a oleira em uma intersecção de dois mundos, o artesanal e o industrial. E descreve sua técnica e produção, além de apontar passagens da vida da mesma. Na segunda metade do século XIX, ocorre a inserção, em maior volume, de artigos de luxo industrializado, de origem europeia. Tal inserção acaba por dificultar o trabalho dos oleiros, pois ocorre a substituição da louça de barro pela faiança ou porcelana. É nesse contexto que a oleira está inserida, entre dois mundos.

\section{Entre dois mundos}

O século XIX foi marcado por grandes transformações, dentre elas a produção de bens de consumo em grande escala, expandindo o modelo europeu de civilidade. A civilidade e o consumo estão diretamente relacionados, possibilitando o surgimento de redes formadas por fabricantes, comerciantes e consumidores. $\mathrm{O}$ período citado caracterizou-se, principalmente pela produção de bens de consumo, estando relacionada a criação e expansão de uma rede de consumo que contribuiu para um aumento na aquisição de artigos de luxo.

Após a revolução Industrial observa-se o crescente aumento de fábricas e a diversidade de itens a serem comercializados, assim como a inserção de artigos europeus que tinham como objetivo distinguir as camadas mais abastadas através de louças, mobilia, vestimenta e manuais de Bom tom ${ }^{5}$ e ainda inserir o modelo europeu de civilidade. É nesse periodo, mais precisamente na segunda metade do século XIX que o Brasil se insere no referido modelo. Tal inserção ocorre em diferentes regiões brasileiras, mas não de forma simultânea, nem tão pouco com a mesma intensidade, como ocorreu no Ceará.

Para melhor registrar as diferentes formas de inserção no modelo acima citado, recorremos ao caso da moça muda, descrita nos relatos de viagem de Francisco Freire Alemão. A relevância da artesã está na forma como ela aparece nas folhas do diário do viajante e o olhar que ele infere sobre a sua práxis, a mesma é uma oleira e produz louça de barro, que se assemelha a louça inglesa. Louça utilizada nos rituais de sociabilidade, como o chá e o jantar (banquetes) ou recepções de grande porte. Até então se percebia apenas uma forma de se inserir em tal modelo, seria através dos modos a mesa ${ }^{6}$, porém a oleira se insere por sua técnica.

No exemplo cearense, observa-se através dos relatos de viajantes as diferentes formas de inserção, como é o caso descrito no diário do médico e botânico Francisco Freire Alemão. Em seus relatos de viagem, o mesmo descreve o cotidiano das famílias em várias cidades e paisagens. O citado médico era membro da Comissão de Exploração, conhecida posteriormente, como Comissão das Borboletas.

A relevância e a composição da referida comissão são evidenciadas por Karoline Viana Teixeira, segundo a autora:

Considerada a primeira viagem científica composta exclusivamente por brasileiros, a Comissão Científica reuniu alguns dos intelectuais e naturalistas mais renomados da época, tendo como área de exploração a província do Ceará, partes de Pernambuco, Piaui e Rio Grande do Norte, além da região do Rio Negro - esta empreendida por iniciativa particular por um de seus membros. Francisco Freire Alemão, Guilherme Schüch de Capanema, Giacomo Raja Gabaglia, Antonio Gonçalves Dias, além do próprio Ferreira Lagos, propositor da viagem exploratória, empreenderam um amplo trabalho de identificação e prospecção de recursos naturais, localização astronômica e geográfica, comércio, agricultura, pecuária, estado de vilas e cidades e condições das tribos indigenas (2015, p. 44). 
No Brasil foram criadas comissões com o objetivo de coletar informações sobre as diferentes regiões brasileiras, destacando-se a Comissão Científica de Exploração criada pelo IHGB (Instituto Histórico e Geográfico Brasileiro), em 1856, com o objetivo de observar, registrar, medir, coletar, analisar, extrair, anotar, calcular, classificar e reunir informações sobre o clima, fauna, flora, relevo, hidrografia, formações geológicas, costumes, etnografia, tradições da população brasileira. Percorreram as províncias brasileiras, a exemplo das comissões estrangeiras que haviam passado anteriormente (ALEMÃO, 2006).

Na província do Ceará, a referida comissão passou entre fevereiro de 1859 a junho de 1861, tendo sido dividida em cinco sessões: zoológica, botânica, astronômica e geográfica, etnográfica e narrativas de viagem, geológica e mineralógica - sendo esses os campos de interesse científico adotado pela Comissão de Exploração. A comissão era composta por Francisco Freire Alemão, o então presidente da comissão, Manoel Francisco Carvalho, Manoel Ferreira Lagos, entre outros.

O registro de tal expedição foi realizado por Freire Alemão (2006, p. 10) que "notabilizou por extensa produção escrita, em especial aquela dedicada ao exame, descrição e classificação de novos gêneros e espécies da fauna brasileira". O mesmo descreveu os costumes, a arquitetura e as relações sociais, políticas e comerciais dos lugares que passava. O historiador Antônio Luiz Macedo ao apresentar o diário de Freire Alemão nas chamadas 'notas explicativas', enfatiza que

na passagem da Comissão Científica pelos rincões do território cearense, seu presidente e chefe da seção botânica não se furtaria a registrar por escrito uma série de impressões, observações, comentários e narrativas concernentes ao clima, relevo, hábitos alimentares, topônimos, condições econômicas, traçado urbano, aspectos a arquitetura vernácula, episódios remotos e recentes que se deram na localidades visitadas, ou em suas cercanias (ALEMÃO, 2006, p. 13).

Ainda segundo Macedo os relatos descritos por Freire Alemão fornecem elementos importantes para História e para Cultura cearense. Os relatos aqui analisados foram a partir da perspectiva o referido médico, o que em comparação com os demais relatos nos permitem perceber o olhar do viajante, e a percepção dele acerca do caso da oleira. O que propomos é perceber o papel da artesã surda-muda apresentada por Freire Alemão e como esse a descreve em seu diário.

\section{Reflexões acerca da prática}

Argumenta-se, com base em estudos da cultura Surda-Muda, que a condição da oleira na verdade contribui para um desenvolvimento aprimorado de outros sentidos que ajudam a explicar a peculiaridade de sua produção - fato este que passa despercebido por seu relator, Freire Alemão. Reforçando esta proposição, aliase uma análise a partir da narrativa do autor sobre; o processo de produção de louças populares; o sistema de práticas de boas maneiras que exigia a renovação de conjuntos de louças; e o contexto do comércio, importação e produção cearense de cerâmica europeia e local.

No ano de 1859, ao visitar a cidade de Icó, distante $301 \mathrm{~km}$ da capital cearense, o viajante e sua comissão tiveram notícia de uma artesã que produzia louça por encomenda e que não se parece com a produzida localmente. De acordo com Bezerra (2015, p. 225) "A notícia de tal produção chega a ele através de uma conversa com a esposa do juiz municipal, que havia nascido em Icó, cidade que mantinha relações comerciais com Aracati", cidade está visitada anteriormente pelo viajante. No relato acima o viajante se refere a moça 'muda' que produzia louça em barro, que a louça fabricada por ela era semelhante à louça inglesa, importada principalmente da Inglaterra, e que era produzida em larga escala.

O viajante e já mencionado e em seu relato expressa a admiração ao observar uma das peças produzidas pela referida 'muda', segundo Freire Alemão

[...] Depois chegou o Lagos, que havia ido de manhã à casa da muda (daqui a quase quatro léguas) para a ver trabalhar uma louça preta de grande perfeição. Diz ela que o acaso a fez descobrir o modo de empretecer a louça. 
Cozinhando-a uma vez com bostas de cavalo (o que não e parece acreditável). Seus pais trabalhavam em louças (potes, panelas etc. etc.) (2006, p. 164).

Em outro relato o viajante descreve com mais detalhes a técnica utilizada na produção da referida louça, por sua artesã, denominada por Freire Alemão de "moça muda", a mesma residia nas proximidades de Forquilha distante $214,1 \mathrm{~km}$ da cidade de Fortaleza, e 354, 5 km de Aracati, e ainda 446,2 km da cidade de Icó.

Um dos pontos que mais chama a atenção é diversidade de itens que ela pode produzir, segundo Freire Alemão

É realmente admirável a perfeição com
que ela os faz, cobrindo-os de relevos
e desenhos elegantes. Tomam uma
cor preta e lustrosa, e firme como a de
uma louça inglesa. O segredo, ao que
parece, consiste nisso simplesmente
e ela não fez mistério: queimava umas
xícaras à vista do Lagos, deste modo
fez uma pequena fogueira de banha e
à roda do fogo ia queimando a louça.
Fez-me um presente de uma jarrinha:
fazendo-a girar continuamente, até que
se achou corada e vermelha, tirou as
brasas e tições, assentou as xicaras
sobre o lugar da fogueira que estava
quente, e depois foi lançando bostas
de cavalo até cobri-las, a bosta entrou
a arder e continuou até consumir-se,
deixando as xicaras empretecidas.
Depois passou-lhes por cima cera de
carnaúba (a de abelhas faz o mesmo
efeito), esfregando-os, e deu o negócio
por concluido. A explicação que me
ocorre é que bosta queimando-se dá
um fumo muito carregado de partículas
de carbono que se insinua da louça,
um pouco abertos em razão do calor;
a cera as firma e dá lustre (20o6, p. 165).

Os trechos acima nos permitem observar a partir da perspectiva do viajante o papel da "mulher muda", onde essa desenvolveu uma técnica de produção de louça de barro que se assemelha a louça importada da Inglaterra. 0 que a insere no modelo europeu adotado pela camada mais abastada da população, porém o que a difere é que não existe relato de que ela e sua familia fizessem uso das referidas louças, apenas as produziam. Ou seja, traduziu a louça inglesa a partir de elementos do seu cotidiano e aplicando uma técnica própria para produzir peças de barro similares as inglesas. Como descreve Freire Alemão (2016, p. 164) "[...] Os instrumentos de que se serve são os mais simples e toscos (e o Lagos trouxe-os para amostra) e com eles faz ela tudo: bules, xicaras, jarros etc. etc., aparelhos completos e conforme os modelos que lhe dão".

Segundo Bezerra a tradução ${ }^{7}$ realizada pela artesã não estava apenas na técnica de produção, mas no resultado. E continua

Outra forma de tradução observada foi através dos tipos de louças produzidas. como informa o viajante que esta fabricava "bules, xicaras, jarros etc." e ainda "aparelhos completos" que se supõe que poderiam ser de chá ou jantar, e ainda "conforme os modelos que the dão", a reprodução de tais peças, acredito, requer um conhecimento da peça a ser fabricada, dessa forma, a referida mulher deveria ter contato e reproduzir tais peças quase regularmente (BEZERRA, 2015, p. 225),

Nos relatos acima, observa-se que a louça produzida pela referida artesão é diferente das fabricadas pelos demais oleiros, e o que mais chama a atenção do viajante além da técnica é que a moça muda não se insere no modelo civilizador através das regras de civilidade, pois esse não as descreve, e sim pela forma que a artesã produz louças lustrosas e que se assemelham às inglesas.

A civilidade proposta pelo modelo europeu, destacando o Ceará, estava relacionada a aquisição e aprendizado das regras através de uma literatura de civilidade, como afirma Bezerra

No Ceará, circulavam os dois modos de civilidade, sendo apresentados da seguinte forma: a pedagógica, através de compêndio de civilidade, ou seja, manuais de etiqueta destinados aos jovens. Quanto aos guias de bom tom, duas obras se destacavam e eram anunciadas nos jornais por livrarias, que as importavam (2015, p. 171).

\footnotetext{
7 O conceito de tradução que mais se assemelha a discussão aqui proposta é a Tradução Cultural, trabalhada pelo historiador Peter Burke, em sua obra Hibridismo Cultural (2003), onde este aponta que a tradução ocorre através das estratégias adotadas por um determinado grupo para domesticar o que não é seu, o que é estrangeiro.
} 
Tais manuais associados aos utensilios de mesa e cozinha, proporcionavam a uma pequena camada da sociedade, sua inserção no modelo europeu de civilidade e consumo, proporcionados pelo capitalismo. A referida inserção ocorria em etapas, sendo a primeira a escolha de itens que os possibilitassem se distinguirem dos demais grupos, em segundo a sua exposição em vitrines ${ }^{8}$ (guardalouças) a partir da compra e uso de aparelhos de jantar, conjuntos de chá e café, e por último o ritual ou seja seu uso em festas, jantares e banquetes.

o caso apresentado por Freire nos chama a atenção além de sua descrição acerca da técnica utilizada pela moça muda, mas por sua inserção no 'mundo' acima apresentado, onde para se diferenciar dos demais grupos sociais, a elite adquiria produtos europeus. No caso em questão se percebe que tais grupos conheciam o trabalho da mesma e o adquiria, como já foi citado anteriormente. A semelhança com os itens europeus proporcionou a circulação de seu trabalho e o conhecimento da técnica utilizada.

Os objetos adquiridos pela referida comissão foram levados ao Rio de Janeiro, dentre eles as louças produzidas pela referida oleira. Porém não foram publicados todas as anotações e relatos da comissão e nem se todos os itens foram expostos, no caso em questão, as louças da referida oleira. Segundo Teixeira

Os produtos trazidos no retorno à Corte foram objeto de várias exposições públicas, tendo sido incluidos na mostra de produtos nacionais levada para a Exposição Universal de 1862, em Londres. Já as coleções trazidas pelos "científicos" ajudaram a incrementar o acervo do Museu Nacional, além de fomentar pesquisas ulteriores (2015, p. 44). ${ }^{9}$

A aquisição das louças produzidas pela referida oleira foi feita devido a técnica por ela utilizada para empretecer a mesma, e ainda por se assemelhar as louças vindas da Europa. Merecendo registro em seu diário e compra de itens para levar a corte. O encontro entre os viajantes Freire e Lagos com a referida artesã é descrito em seu diário, como veremos a seguir.

\section{Audição e observação: materiais em transformação}

É um tanto paradoxal a aparição desse evento nos registros realizados por Francisco de Freire Alemão (1797-1874) durante suas viagens naturalistas no agreste cearense no ano de 18591860. O seu Diário, editado e publicado em 2006, contém apenas três excertos do encontro com a surda-muda que competem com as apuradas descrições da fauna, da flora e da sociedade do Ceará. Apesar de representarem observações pontualíssimas e basicamente essenciais, o caso é o único que parece nutrir uma certa antecipação, como se vê primeiro na entrada do dia 8 de setembro de 1859:

De noite fui eu e Manoel visitar o juiz municipal, cuja senhora é filha do Icó [cidade], mui amável e está de viagem para o Icó, provavelmente para ter lá o seu bom sucesso, estando com o ventre muito adiantado. [...] Soubemos aí que, antes de chegar-se ao Icó, há uma mulher muda que trabalha em louça admiravelmente, fazendo tudo o que se the encomenda e segundo o modelo que se lhe dá, que a louça é mui preta e lustrosa (ALEMÃO, 2006a, p. 81).

...e um mês depois, no dia 8 de novembro:

[...] Depois chegou o Lagos, que havia ido de manhã à casa da muda (daqui a quase quatro léguas) para a ver trabalhar com grande perfeição. Diz ela que um acaso a fez descobrir o modo de empretecer a louça, cozinhando-a uma vez com bostas de cavalo (o que não me parece acreditável). Seus pais trabalhavam em louça (potes, panelas etc. etc.). Os instrumentos de que se serve são os mais simples e toscos (e o Lagos trouxe-os para amostra) e com eles faz ela tudo: bules, xicaras, jarros etc. etc., aparelhos completos e conforme os modelos que lhe dão. É realmente admirável a perfeição com

8 Usamos o termo 'vitrine', pois as louças ficavam expostas em um guarda-louça que era feito de madeira com porta de vidro, trazidos da Europa. Tais móveis oram criados segundo Daniel Roche (2000), com a finalidade de expor tais itens. Assim como outros itens da sala de jantar foram pensados a partir da criação da sala de jantar. (Ver ROCHE. Daniel. História das coisas banais, o nascimento do consumo séc. XVII-XIX. Rio de Janeiro: Rocco, 2000)

9 As coleções eram compostas de minerais, animais e outros. Existiam uma rivalidade quanto a criação da referida comissão, considerando que era formada por "cientistas" diferente das demais. 
que ela os faz, cobrindo-os de relevos e desenhos elegantes. Tomam uma cor preta e lustrosa, e firme como a de uma louça inglesa. O segredo, ao que parece, consiste nisso simplesmente e ela não fez mistério: queimava umas xícaras à vista do Lagos, deste modo fez uma pequena fogueira de banha e à roda do fogo ia queimando a louça. Fez-me um presente de uma jarrinha: fazendo-a girar continuamente, até que se achou corada e vermelha, tirou as brasas e tições, assentou as xícaras sobre o lugar da fogueira que estava quente, e depois foi lançando bostas de cavalo até cobri-las, a bosta entrou a arder e continuou até consumir-se, deixando as xicaras empretecidas. Depois passou-lhes por cima cera de carnaúba (a de abelhas faz o mesmo efeito), esfregando-os, e deu o negócio por concluído. A explicação que me ocorre é que bosta queimando-se dá um fumo muito carregado de partículas de carbono que se insinua da louça, um pouco abertos em razão do calor; a cera as firma e dá lustre. O Lagos me deu uma jarrinha (ALEMÃO, 2006a, p. 165).

...e enfim, um bom tempo depois, nos dias 20 e 21 de abril de 1860:

Cheguei a Forquilha além casa de Francisco [palavra apagada], cuja cunhada é a mouca, ou tartamuda, que trabalha em louça tão belamente. "Era perfeita", diz-me a irmã, "até idade de 10 anos". Teve nesse tempo uma grande dor de ouvido e ao mesmo tempo úlceras na garganta, donde resultou ficar mouca e quase muda, ou antes podendo apenas pronunciar uma, outra palavra curta, como acabou-se, mas fala de modo a só certas pessoas das casas poderem-na compreender. Comprei-lhe algumas peças mais fáceis de conduzir, mas o que mais estimei foi vê-la trabalhar nos desenhos num copo: é admirável como com umas pedrinhas, sementes de mucunã e uns ferrinhos, faquinhas e goivinhos de pau, ela faz tudo; e sem risco nem mudados faz os desenhos, ramos e flores, com a maior presteza e com a mais admirável certeza e simetria. Furtei-lhe de sua cabaça uma pedrinha e uma mucunã. [...]

Levantamo-nos cedo e mandamos aprontar os animais, tomamos uma xícara de café com um pão e manteiga; ao despedir-nos, perguntamos à Sra. Maria Joaquina quanto the deviamos pelo jantar que nos deu ontem - galinha cozida e arroz -, disse-nos que não era nada, então pedimos licença para oferecer a sua Chiquinha um lenço de seda (foulard francês) de que a menina se mostrou contente. Dei ao pequeno José uma moeda de 500 tostões e à mouca, pela louça que the comprei no custo de $1 \$ 920$, dei três mil-réis em prata. Voltou ela trazendo-me uma cuia de presente e a linda Francisquinha, uma quartinha, ou moringuinha (ALEMÃO, 2006b, p. 94-95).

Além da linearidade e antecipação - talvez reveladas de forma um tanto involuntária por Freire Alemão - pode-se perceber, primeiramente, que o gatilho da sua visita foi a notícia da existência de uma determinada artesã da olaria que criava uma louça de caracteristicas particulares; a sua cor preta. Não obstante, o outro traço inicial de curiosidade instintiva está relacionado a prática da cópia; ou seja, da replicação serial e 'exata' de peças em louça. 'Exata', bem entendido, porque justamente a louça era preta e isso parecia uma particularidade notável; a contradição paradoxal entre cor, forma e acabamento.

Na segunda citação entra em cena o insólito material que é ingrediente para o fabrico da louça: os excrementos de cavalo; assim como o seu processo de fabricação. A manipulação dos materiais, feita às claras - ao contrário do que parecia supor Freire Alemão - incrementa e emoldura o inconcebivel efeito tecnológico ${ }^{10}$ que os excrementos exercem sobre a forma recém estabilizada do pote. A perícia da surda-muda no fabrico, certamente desenvolvida junto à familia de oleiros a qual pertencia, não encontra voz por si mesma além de seus atos: o desvelo inicial de sua obra é descrito em primeira pessoa, muito embora Freire Alemão não estivesse presente, pois quem testemunha é Lagos seu "braço-direito" 11: "É realmente admirável a perfeição com que ela os faz, cobrindo-os de relevos e desenhos elegantes. Tomam uma cor preta e lustrosa, e firme como a de uma louça inglesa ${ }^{12 "}$. Após esse traçado de motivos sobre a superficie crua do pote, o cozimento é

10 Onde 'Tecné', em grego, significa fazer aparecer. HEIDEGGER, 1971, p. 157

11 A Comissão era formada por membros de diferentes áreas, como citado anteriormente, sendo Lagos o mais próximo da Freire e que se destaca nos relatos do viajante.

12 Embora ele também testemunhe os gravados, isso só acontece na terceira citação, no início do ano seguinte. 
realizado em duas etapas que consistem em: uma queima externa ("a roda do fogo ia queimando a louça"); e uma espécie de 'forno' que é feito com o seu próprio combustivel de excrementos equinos (possivelmente secos). Isto finalmente confere a mudança de cor do vermelho cinerário para o preto, quase finalizado. As duas queimas exigem diferentes relações de proximidade com a argila em transformação. Antes, o forte calor corante das chamas de banha animal foi respeitado; mas quando arrefecido, se tornou o berço das xicaras pré-cozidas e de seu curioso 'forno'. Das fumaças emergentes dessa alquimia surgem as xicaras pretas, que vão receber uma 'pele' lustrosa, feita a aplicação de cera de carnaúba. O efeito só aparenta ser apenas "acreditável" quando Freire Alemão teoriza sobre a influência e combinação dos elementos dispostos na narrativa de Lagos - o que não explica, afinal, por que são usados excrementos, se provavelmente existiam outros materiais com propriedades cromáticas obscurescentes para ser utilizados; e.g. carvão mineral.

A terceira citação nos dá conta do entorno onde reside a surda-muda. Chama muito a atenção o fato de sua familia inteira ser nomeada, menos ela. Não obstante isto, em virtude da negativa da matriarca de ser paga pela hospitalidade e alimentação, inicia-se uma série de dádivas sobre a surda-muda e seu casal de irmãos.

A irmã dela ensaia uma origem para sua deficiência, nos contando como ela foi reduzida de uma condição de pessoa falante e ouvinte para uma de surda-muda, através de patologias cuja origem não é explicada. Esclarece-se que, afinal, ela se comunica verbalmente de forma bastante limitada, e compreensivel apenas aos seus. Isto ressalta que ela, afinal, não nasceu surda, mas transitou para isto. Não obstante, sua situação limitrofe entre a compreensão e incompreensão era equilibrado parcialmente pela quantidade de possibilidades de interação que emergiam da sua aparente limitação sensivel:

Deaf people have accumulated a set of knowledge about themselves in the face of the larger society's understanding - or misunderstanding - of them. They have found ways to define and express them- selves through their rituals, tales, performances and everyday social encounters (PADDEN; HUMPHRIES, 2005, p. 11),

A moça muda, portanto, mobilizava não apenas o pouco saber falante que the foi oportunizado, mas subvertia a desvantagem de sua atual condição através da comunicação e atração por outras formas de interatividade. Ao copiar a louça estrangeira, imbricando nela um estilo particular, senão único, ela apresenta e mobiliza diálogo com todas as camadas sociais e conhecimentos técnicos do periodo - mesmo que imersos na ilusória inocência da atividade artesanal. Diversos panoramas podem ser perscrutados a partir disso. O primeiro se coloca na relação intermediária da sua cidade, Forquilha, e outros dois centros comerciais e culturais do Ceará: Icó e Fortaleza, por onde passava o grosso da louça inglesa destinada às classes de alta estirpe e conta bancária. Sua louça marginal chamou a atenção de um notório membro dessa classe, que é o que nos fornece a informação, Freire Alemão. Mas também sua louça poderia ser útil em um caráter ascensionista, ao possibilitar às pessoas de menor condição social a possibilidade de ensaio de alguns dos elaborados rituais de modos à mesa e boas maneiras. Assim, existe uma mobilização das tensões entre caracteres funcionais e estéticos da louça artesanal, assim como um incentivo à releitura da norma social aceita em prol de uma subversão que, embora incipiente e tão muda quanto sua fabricante, também não passou despercebido. Mas outras considerações sensiveis podem ser pensadas:

Adaptational theories are useful when
considering how Deaf culture might be
reactive to the majority of culture and its
actions. Likewise, if one considers that
the 'Deaf environment' is the 'hearing'
world by which they are surrounded,
adaptational strategies may form an im-
portant part of individual and collective
Deaf life. However, they do not address
how such strategies might be assessed,
thus requiring us to examine the potential
of ideational theories (LADD, 2003, p. 202).

Há uma máxima que jamais pode ser universal, e que por isso mesmo se aplica aqui: a retirada de um 
sentido promove a exacerbação de outros. Como exemplo, podemos comentar a relação sensivel entre odores e sabores: a louça branca tradicional era utilizada em um ambiente onde o cheiro dos alimentos preparados vêm à consciência, com travessas cheias de assados recheados, pratos fundos com sopas fumegantes, xicaras e pires sustentando chás ingleses com leite contrastam fortemente com o preparo, por sua vez, da louça artesanal. O uso de excrementos animais (ou banha), por si só já parece exótico o suficiente se a fuligem e suas flâmulas de fumaça não se dispusessem na residência da moça surda. A cor branca das louças importadas, a marrom escurecida das locais e a preta da surda-muda, são suportes sensiveis associados ao cheiro dos jantares e da bosta; enquanto para a muda, o cheiro da bosta era relativo ao ato de cozinhar a louça, para Freire Alemão, é o fato de ela ter sido feita com bosta que cria a sensação de novidade, já que ele só come o cozido das louças.

Isso nos leva a uma última especulação: a subversão da objetificação. Independentemente do grau de sua ciência acerca dos ritos aceitáveis e típicos do periodo, a moça muda parece ter plena noção da cisão de sua influência social entre objeto e individuo. Podemos inferir isso com a mais sincera volição de Freire Alemão de conhecer a moça apenas depois de conhecer suas obras. É muito provável que ela não soubesse ler, porém, ninguém jamais poderá afirmar que ela não reinventou o cartão de visitas.

\section{O cheiro da louça e a surdez materializante}

Os conjuntos de louças estão relacionados com os rituais de comensalidade, como: os jantares fastidiosos e cheirosos e os bailes - contraste com a louça da surda-muda. A louça adquirida pela camada abastada diferente da produzida pela oleira pela técnica aplicada na produção da mesma, mas a forma e aspectos se assemelham as europeias. Os rituais de comensalidade seguiam o modelo europeu, dentre eles: destaca-se o jantar, tendo sido este incorporado do cotidiano europeu. Para atender às necessidades do referido ritual, foram agregados diferentes itens para compor a mesa, como aparelho de jantar, copos de cristais, talheres (garfos, facas e colheres), tigelas, sopeira, entre outros. A diversidade de itens e modelos possibilitou uma distinção social através dos objetos, pois nem todos os grupos podiam adquirir produtos com a mesma qualidade (BEZERRA, 2015, p. 198)

O modelo europeu de civilidade e consumo adotado nas diferentes partes do mundo chega à cidade de Aracati através dos rituais de comensalidade, destacando o jantar. Os itens de mesa e cozinha descritos acima, e com eles as regras impostas, incluem diferentes formas de por a mesa e saber se como se comportar, para tanto são ensinadas tais regras nos manuais de civilidade que circulavam nas escolas e nas casas das familias mais abastadas. Além das regras de civilidade, os itens de mesa e cozinha são elementos de distinção social, a inserção de itens, como o guarda-louças possibilita compreender como a sociedade em questão exibe tais itens, o móvel citado pode ser observado como uma vitrine, onde aparelhos de jantar são expostos para que seus pares possam contemplar e/ou mostrar seu status e seu papel na sociedade.

Diante desse quadro observa-se como a oleira se insere nesse modelo através das louças encomendadas e que se assemelham as inglesas, porém se diferenciam pela técnica empregada por ela. A bosta de cavalo para fazer louça implica na utilização e percepção de qualidades desse elemento como algo que não pode ser notado por Ouvintes - muito embora a surda-muda provavelmente possuísse tanto olfato quanto Freire Alemão. Para a surda-muda, parece que a bosta era um elemento constitutivo essencial da cerâmica ${ }^{13}$, tanto quanto o antiplástico ou a própria argila. Isto foi percebido por Freire Alemão pelo insólito que representava; muito mais do que habilidade dela de replicar cópias de louças diversas. A escurecida conexão entre argila crua, bosta e fogo é o centro

13 Quanto à técnica de produção cerâmica utilizada por outros ceramistas no Brasil (ver SCHEUER, Herta Loëll. Estudo da cerâmica popular do Estado de São Paulo. São Paulo: Conselho Estadual de Cultura, 1976; E SCHEUER, Herta Loëll. A Tradição da Cerâmica Popular. Curitiba, Paraná: Livramento Escola de Folclore, 1982) 
nervoso da articulação das visões de mundo de ambas personagens. Se para a surda-muda era material construtivo fundamental do seu oficio, que the garantia uma subjetividade além da necessidade de palavras; para o citadino era uma revelação de que a bosta empresta qualidades à louça que ele sequer imaginava.

Para Freire Alemão, o fato de ela ter sido feita com bosta que cria a sensação de novidade, já que ele só come o cozido das louças. Nesta levada, a cor preta da louça se incorpora ao mundo do consumo e civilidade apresentado anteriormente, e se insere a mesa e os modos da sociedade cearense.

\section{Considerações finais}

Os relatos de Freire Alemão permitem conhecer um outro mundo inserido dentro de um modelo de civilidade e consumo, na segunda metade do século XIX, no Ceará, onde uma oleira surdamuda que residia próximo à cidade de Forquilha, utiliza uma técnica de produção de uma louça empretecida que imita uma louça inglesa, sendo inserida em dois mundos aqui apresentados. A proposta deste artigo é iniciar uma discussão acerca do viés sensorial-fenomelógico e como este pode ser trabalhado na arqueologia, como foi exposto aqui através da oleira surda-muda.

\section{Referências}

ALEMÃO, Francisco Freire. Diário de viagem de Freire Alemão: Fortaleza - Crato: [s. n.], 1856. (Fac-símile) Fortaleza: Museu do Ceará, Secretaria de Cultura do Estado do Ceará, 2006.

BEZERRA, Ana Paula Gomes. Capitalismo e elite no Ceará: produção, distribuição e consumo de louças europeias em Aracati (1850 a 1890). 2015. (Dissertação de Mestrado) - Estrado Acadêmico em História, Universidade Estadual do Ceará, 2015.

BURKE. Peter. Hibridismo Cultural. São Leopoldo: Ed. UNISINOS, 2008. (Coleção Aldus 18).

CONSTANTINO, Núncia Santoro de. Relatos de Viagem como fontes à História. Porto Alegre: EDIPUCRS, 2012.

HEIDEGGER, Martin. Poetry, Language, Thought. New York: Harper \& Row. 1971.
HOLBRAAD, Martin. Ontology, ethnography, archaeology: na afterword on the ontography of things. Cambridge Archaeological Journal. Cambridge, v. 19. n. 3. p. 431-441, Oct. 2009. https://doi.org/10.1017/ Sog59774309000614.

LADD, Paddy. Understanding Deaf Culture: in search of deafhood. Clevedon: Multilingual Matters LTD. 2003. https://doi.org/10.1017/S0959774309000614.

LADD, Paddy. Em busca da Surdidade I. Colonização dos Surdos. Tradução Mariani Martini. Lisboa: Surd"Universo, 2013

MACEDO, Antonio Luiz. Introdução. In: ALEMÃO, Francisco Freire. Diário de viagem de Freire Alemão: Fortaleza - Crato: [s. n.], 1856. Fortaleza: Museu do Ceará, Secretaria de Cultura do Estado do Ceará, 2006. (Fac-simile).

MINUZZI, João Davi Oliveira; TOMAZI, Taís Giacomini. Limites e possibilidades no uso de fontes históricas: batismos, inventários e relatos de viagem. História: Unicap, Recife, v. 3, n. 6, jul./dez. de 2016. https://doi. org/10.25247/hu.2016.v3n6.p337-350.

PADDEN, Carol A.; HUMPHRIES, Tom L. Inside Deaf Culture. Cambridge: Harvard University Press, 2005.

ROCHE. Daniel. História das coisas banais, o nascimento do consumo séc. XVII-XIX. Rio de Janeiro: Rocco, 2000.

SCHEUER, Herta Loëll. Estudo da cerâmica popular do Estado de São Paulo. São Paulo: Conselho Estadual de Cultura, 1976.

SCHEUER, Herta Loëll. A Tradição da Cerâmica Popular. Escola de Folclore: Ed. Livramento, 1982.

SCHWARCZ, Lilia Moritz. Introdução. In: ROQUETTE, J. I. Código do Bom-Tom: ou Regras da civilidade e de bem viver no século XIX. São Paulo: Companhia das Letras, 1997

SOARES, Fernanda Codevilla; Corção, Mariana. Bom gosto à mesa: cultura material e distinção social no Brasil do século XIX. Clio. Série Arqueológica (UFPE), Pelotas, v. 27, p. 33-62, 2012. https://doi. org/10.15448/2178-3748.2015.2.21902.

TEIXEIRA, Karoline Viana. Percepções e limites do fazer científico: o caso da Imperial Comissão Cientíica de Exploração (1859-1861). Oficina do Historiador, Porto Alegre, EDIPUCRS, v. 8, n. 2, p. 43-59, jul./dez. 2015.

\section{Ana Paula Gomes Bezerra}

Doutoranda em História pela Pontificia Universidade Católica do Rio Grande do Sul (PUCRS, Porto Alegre, RS, Brasil); Coordenadora do G.T. Cultura Material e Arqueologia (Associação Nacional de História - Seção Rio Grande do Sul, Brasil (ANPUH RS).

\section{Filipi Pompeu}

Doutorando em História pela Pontifícia Universidade Católica do Rio Grande do Sul - PUCRS, Porto Alegre, RS, Brasil 


\section{Endereço para correspondência}

Ana Paula Gomes Bezerra/ Filipi Pompeu

Pontifícia Universidade Católica do Rio Grande do Sul

Av. Ipiranga, 6681, Prédio 40

Partenon, 90619900

Porto Alegre, RS, Brasil 